\title{
A quadruplex-DNA binder functionalised with a SPECT probe for in vivo
}

\section{imaging}

\author{
Rainbow Lo ${ }^{1,2}$, Gilbert O. Fruhwirth ${ }^{1 *}$ and Ramon Vilar ${ }^{2 *}$ \\ ${ }^{1}$ Imaging Therapies and Cancer Group, Comprehensive Cancer Centre, School of Cancer \\ and Pharmaceutical Sciences, King's College London, SE1 1UL London, UK. \\ ${ }^{2}$ Department of Chemistry, Molecular Sciences Research Hub, White City Campus, Imperial \\ College London, W12 OBZ London, UK.
}

*Corresponding authors: gilbert.fruhwirth@kcl.ac.uk and r.vilar@imperial.ac.uk

\begin{abstract}
Guanine-rich sequences of DNA can fold into intramolecular tetra-helical assemblies known as G-quadruplexes (G4). Their formation in vivo has been associated to a range of biological functions and therefore they have been identified as potential drug targets. Consequently, a broad range of small molecules have been developed to target quadruplexes. However, to date, there is very limited information of the biodistribution of quadruplex binders in whole organisms. Here, we report the functionalisation of a well-established G4 DNA binder (based on a square planar platinum(II)-salphen complex) with two different radiolabelled complexes. An ${ }^{111}$ In-conjugate was successfully used to assess its in vivo distribution in a mouse tumour model using single-photon emission computed tomography (SPECT) imaging. These studies have shown the overall biodistribution of the G4 DNA binder highlighting its accumulation in the tumour.
\end{abstract}


Besides its canonical double stranded structure, DNA can fold into several other topologies. One of these, the guanine-quadruplex (G4) DNA, has attracted significant interest over the past two decades due to its proposed roles in telomere maintenance, gene expression and replication amongst others. ${ }^{[1-4]}$ Because of these functions, G4s have also been studied as drug targets ${ }^{[1,5-}$ 7] and therefore many molecules have been designed and developed to bind to this DNA structure. ${ }^{[8-10]}$ Some of these molecules have been further studied via biochemical and cellular assays to establish whether their affinity to G4s is retained in a cellular environment leading to a biological function. A particularly attractive sub-class of G4 binders are luminescent molecules that change their optical properties (e.g. emission intensity or lifetime) upon DNA binding. ${ }^{[11-14]}$ Such molecules have been widely studied using in vitro biophysical assays and, in some cases, have been investigated in cells providing valuable information of G4 formation and function. ${ }^{[15-17]}$

While most G4 binders were initially based on polyaromatic organic compounds, several metal complexes have also been shown to display excellent G4 binding capabilities. ${ }^{[18,19]}$ Besides their structural role, the metal centre can confer unique properties (e.g. optical, catalytic, redox) to this type of compounds, which in turn can be very useful in studying quadruplexes. Metal complexes coordinated to Schiff bases (e.g. salphen $\mathrm{L}^{1}$ - see Scheme 1) have been studied in depth as G4 DNA binders, with some of these complexes showing high affinity and selectivity for quadruplexes in vitro and a range of cellular effects. ${ }^{[20-30]}$ In particular, square planar $\mathrm{Pt}^{\mathrm{II}}-$ salphen complexes (see Figure 1) possess a range of properties that makes them suitable as G4 optical probes and potential anticancer agents. For example, some of these complexes target the G4 sequence in the promoter region of the $c-M y c$ oncogene and downregulate its expression. ${ }^{[22]}$ Moreover, several $\mathrm{Pt}^{\mathrm{II}}$-salphen derivatives have been shown to be cytotoxic against a range of cancer cell lines, ${ }^{[31,32]}$ including some examples where the compounds are phototoxic. ${ }^{[33]}$ In addition, these complexes display a luminescent switch-on effect upon 
binding to G4 DNA, which has proven very useful in studying their interactions both in vitro and in cells.

In spite of these advances, currently, the evaluation and real-time distribution of G4 binders in vivo (i.e. in whole organisms rather than cell culture) has been limited to a handful of studies using whole-body fluorescence imaging. ${ }^{[34,35]}$ Limitations from these studies were that signals from optical probes suffered from restricted tissue penetration, increased photon scatter, and thus overall very limited sensitivity. Although imaging modalities that make use of radionuclide probes such as positron emission tomography (PET) or single-photon emission computed tomography (SPECT) do not present these issues, to the best of our knowledge, they have not been previously applied to study the in vivo distribution of G4 binders in whole organisms. We note that a recent paper reported the successful conjugation of a Pt-terpyridine G4 binder with NOTA- ${ }^{64} \mathrm{Cu}$ as a chemo-radiotherapeutic agent with high in vitro activity against cancer cells - although no in vivo PET imaging studies were presented. ${ }^{[36]}$

With the aim of studying the biodistribution of a well-established G4 binder, herein we report the synthesis of two new radiolabelled $\mathrm{Pt}^{\mathrm{II}}$-salphen complexes (6 and 7) and show that they retain the G4 DNA binding properties of the unsubstituted parent complex (1). We also present SPECT-CT imaging data (in vivo and ex vivo) in a mouse tumour model demonstrating the overall in vivo distribution of the G4 DNA binder, thereby also highlighting its accumulation in the tumour.

Our new imaging probes contain a $\mathrm{Pt}^{\mathrm{II}}$-salphen complex (i.e. a G4 binder) tethered to dodecane tetraacetic acid (DOTA). The two components are connected via strain-promoted alkyne-azide cycloaddition (SPAAC) chemistry as shown in Scheme 1. In addition, a symmetrical, unmodified (without linker or DOTA) control complex (1) was synthesised for comparison (Scheme 1). 
A
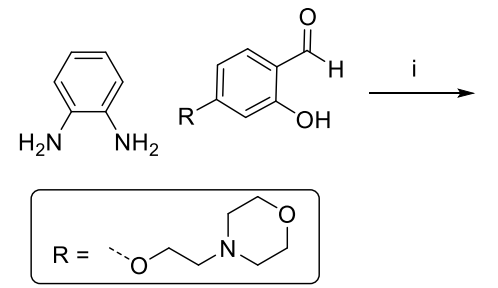

B

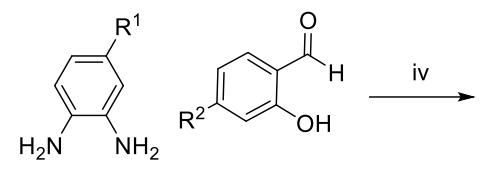

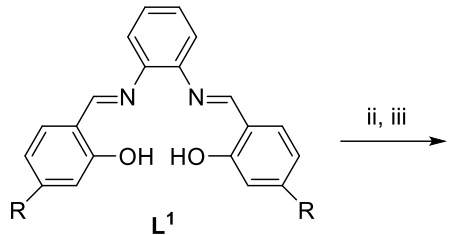

$L^{1}$

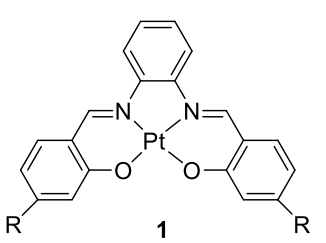

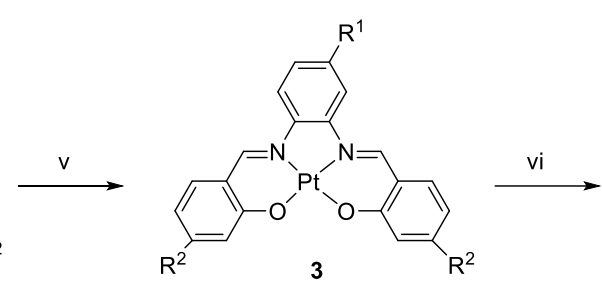<smiles>[R]CC(C)NC(C)COCC(C)(C)CN=[N+]=[N-]</smiles>

O DOTA

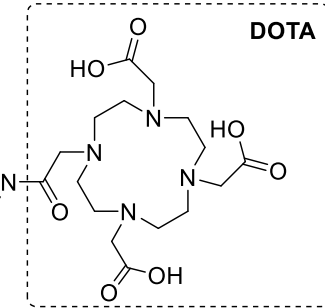<smiles></smiles>

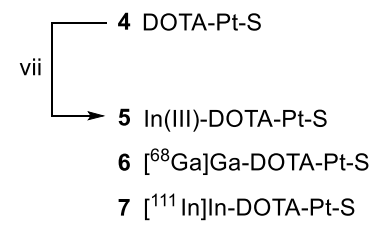

Scheme 1 Synthesis of A) platinum(II) salphen (Pt-S) and B) DOTA-functionalised platinum(II) salphen (DOTA-PtS) complexes. Reagents and conditions: i) $\mathrm{MeOH}$, reflux, $12 \mathrm{~h}$; ii) $\mathrm{NaOAc}, \mathrm{MeCN}, 60{ }^{\circ} \mathrm{C}, 10 \mathrm{~min}$; iii) $\mathrm{K}_{2} \mathrm{PtCl}_{4}, \mathrm{DMSO}$, $6 \mathrm{~h}$; iv) $\mathrm{Zn}(\mathrm{OAc})_{2} \cdot \mathrm{H}_{2} \mathrm{O}$, MeOH, reflux, $6 \mathrm{~h}$; v) $\mathrm{PtCl}_{2}$, DMSO, $90^{\circ} \mathrm{C}, 5$ days; vi) BCN-DOTA (BCN = Bicyclononyne, DOTA = dodecane tetraacetic acid), DMSO, RT, $2 \mathrm{~h}$; vii) Cold reference complex $-\mathrm{InCl}_{3} \cdot \mathrm{x} 4 \mathrm{H}_{2} \mathrm{O}$, radiolabelled complex $-{ }^{68} \mathrm{Ga}$ or ${ }^{111} \mathrm{In}, 0.2 \mathrm{M} \mathrm{NaOAc}$ buffer ( $\mathrm{pH} \mathrm{4.5),} 90^{\circ} \mathrm{C}, 30 \mathrm{~min}$. RT = room temperature. All spectroscopic and analytical data for the characterisation of the compounds shown here can be found in the Electronic Supplementary Information (Figures S1 to S21).

The $\mathrm{Pt}^{\mathrm{II}}$-salphen complex 3, bearing an azide handle for click chemistry, was synthesised via transmetallation of the corresponding $\mathrm{Zn}^{\mathrm{II}}$-salphen complex 2 with $\mathrm{PtCl}_{2}$. BCN-DOTA was then rapidly attached to 3 through SPAAC chemistry within 30 minutes. DOTA-modified $\mathrm{Pt}^{\mathrm{II}}$ salphen (4) was obtained with $>95 \%$ purity, as characterised by HPLC and high-resolution mass spectrometry (HRMS) - see Figure S19 and S20). The non-radioactive 'cold' reference compound 5 was prepared from the metallation of $\mathbf{4}$ with In $^{\mathrm{III}}$ respectively and characterised via HPLC and HRMS (see Figure S21). Complexes 1, 3 and 4 were fully characterised by ${ }^{1} \mathrm{H}-$ 
, ${ }^{13} \mathrm{C}$ - and ${ }^{195} \mathrm{Pt}-\mathrm{NMR}$ spectroscopy and ESI-MS, and their purity established by elemental analysis and/or LC-MS. Radiolabelling of 4 with ${ }^{68} \mathrm{Ga}$ and ${ }^{111}$ In to synthesise 6 and 7 is discussed below.

The DNA binding of unmodified complex $\mathbf{1}$ and the non-radioactive di-metal complexes $\mathbf{5}$ was assessed by biophysical assays. Spectrofluorimetric titrations were carried out based on the well-establish emission switch-on effect that $\mathrm{Pt}^{\mathrm{II}}$-salphen complexes normally display upon binding to DNA. ${ }^{[22,29,31,32]}$ In total, seven G4 DNA structures including parallel $(c-M y c$ and ckit-2), hybrid (bcl-2, htelo.K), antiparallel (htelo.Na, HRAS1, 22CTA) as well as duplex DNA (ds26) were tested (see Table $\mathrm{S} 1$ for sequences). The binding isotherms for the $\mathrm{Pt}{ }^{\mathrm{II}} / \mathrm{In}^{\mathrm{III}}$ complex 5 are shown in Figure 1a. The best binding $\left(\mathrm{K}_{\mathrm{a}}\right.$ ranging $\left.10^{6}-10^{7} \mathrm{M}^{-1}\right)$ was observed for $c-M y c$, ckit-2 (both parallel) and $b c l-2$ (mixed hybrid). In contrast, binding to anti-parallel structures was less favourable $\left(\mathrm{K}_{\mathrm{a}} c a .10^{5} \mathrm{M}^{-1}\right)$ and was worst for $d s 26$, which could not be calculated due to its negligible interaction with $\mathbf{5}$. A summary of $\mathrm{K}_{\mathrm{a}}$ values for the parent Pt complex $\mathbf{1}$ and the Pt-In complex 5 is displayed Figure 1B. Overall, all $\mathrm{Pt}^{\mathrm{II}}$-salphen complexes possessed similar binding profiles indicating there were minimal differences in DNA-binding between the unsubstituted complex (1) and the one modified with DOTA-In ${ }^{I I I}(\mathbf{5})$. This indicated that conjugating the chelator enabling radiolabelling for PET/SPECT imaging to the $\mathrm{Pt}^{\mathrm{II}}$-complex did not alter its affinity and selectivity for G4 DNA. 
A

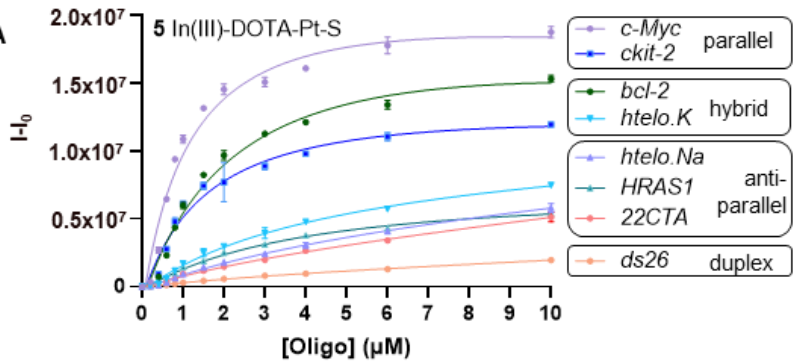

B

\begin{tabular}{ccc}
\hline Oligo & $\mathbf{1}$ & $\mathbf{5}$ \\
\hline c-Myc & $1.41 \pm 0.14 \times 10^{7}$ & $2.10 \pm 0.27 \times 10^{7}$ \\
ckit-2 & $7.15 \pm 0.80 \times 10^{6}$ & $1.03 \pm 0.15 \times 10^{7}$ \\
\hline bcl-2 & $6.19 \pm 0.69 \times 10^{6}$ & $9.70 \pm 0.96 \times 10^{6}$ \\
htelo.K & $2.20 \pm 0.11 \times 10^{6}$ & $2.02 \pm 0.18 \times 10^{6}$ \\
htelo.Na & $2.58 \pm 0.30 \times 10^{8}$ & $9.61 \pm 0.59 \times 10^{5}$ \\
HRAS1 & $1.70 \pm 0.13 \times 10^{6}$ & $1.96 \pm 0.11 \times 10^{6}$ \\
\hline 22CTA & $2.80 \pm 0.14 \times 10^{5}$ & $7.07 \pm 0.83 \times 10^{5}$ \\
ds26 & n.d. & n.d. \\
\hline
\end{tabular}

C

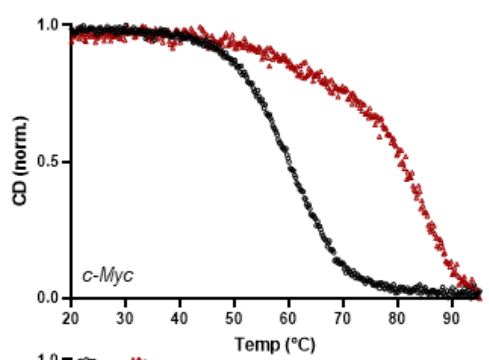

D

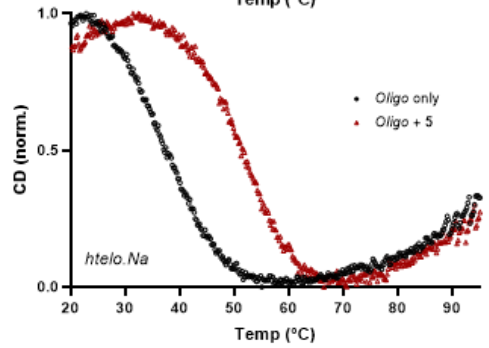

Figure 1. DNA binding experiments. Left: A) Binding isotherms of complex $5(2 \mu \mathrm{M})$ with a range of $\mathrm{G} 4$ structures including parallel (c-Myc and ckit-2), hybrid (bcl-2, htelo.k), antiparallel (htelo.Na, HRAS1, 22CTA) and duplex (ds26) in the appropriate $10 \mathrm{mM}$ LiCaco buffer, at pH 7.3. Oligonucleotide concentration $0.2-10 \mu \mathrm{M} ; \lambda_{\mathrm{ex}}=375$ $\mathrm{nm}, \lambda_{\mathrm{ex}}=500-700 \mathrm{~nm}$. B) Summary of $K_{\mathrm{a}}$ values for 1 and $\mathbf{5}$ respectively. Right: CD melting spectra of G4 DNA $(5 \mathrm{mM})$ in the presence of $25 \mathrm{mM}$ complex 5 (red trace) in the appropriate $10 \mathrm{mM}$ LiCaco buffer (pH 7.3; $1 \mathrm{mM}$ $\mathrm{KCl}$ and $99 \mathrm{mM} \mathrm{LiCl}$ for c-Myc and $10 \mathrm{mM} \mathrm{NaCl}$ and $90 \mathrm{mM} \mathrm{LiCl}$ for htelo. $\mathrm{Na}$ ). C) c-Myc, and D) htelo.Na.

Circular dichroism (CD) melting experiments were also conducted to confirm the G4 DNA binding properties of 5; the studies were performed with $c-M y c$ (parallel) and htelo.Na (antiparallel) as representative examples of the two G4 topologies. As can be seen from Figures 1C and $1 \mathrm{D}$, compound 5 stabilised both structures, with $\Delta \mathrm{T}_{\mathrm{m}}$ values of $20.9 \pm 0.6{ }^{\circ} \mathrm{C}$ and $13.6 \pm$ $0.4{ }^{\circ} \mathrm{C}$ for $c-M y c$ and htelo. $\mathrm{Na}$ respectively. This data corroborates results obtained from spectrofluorimetric titrations indicating that the novel di-metallic complex $\mathbf{5}$ is a very good binder for G4s (particularly $c-M y c$ DNA).

Having established that attachment of the DOTA-In ${ }^{\mathrm{III}}$ moieties to the $\mathrm{Pt}^{\mathrm{II}}$-salphen complex did not impact on G4 DNA binding properties, we proceeded to synthesise the radiolabelled derivatives. $\left[{ }^{68} \mathrm{Ga}\right] \mathrm{Ga}-\mathrm{DOTA}-\mathrm{Pt}-\mathrm{S}(\mathbf{6})$ and $\left[{ }^{111} \mathrm{In}\right] \mathrm{In}-\mathrm{DOTA}-\mathrm{Pt}-\mathrm{S}$ (7) were obtained by heating 4 with either ${ }^{68} \mathrm{GaCl}_{3}$ or ${ }^{111} \mathrm{InCl}_{3}$ in $0.2 \mathrm{M}$ sodium acetate buffer ( $\mathrm{pH} 4.5$ ) for $30 \mathrm{~min}$. The 
radiochemical yields (RCY) were $96.5 \pm 3.6 \%$ and $97.4 \pm 2.6 \%$ for 6 and 7 respectively (mean $\pm \mathrm{SD}, \mathrm{N}=3$ ), as established by radio-HPLC (Figure 2).
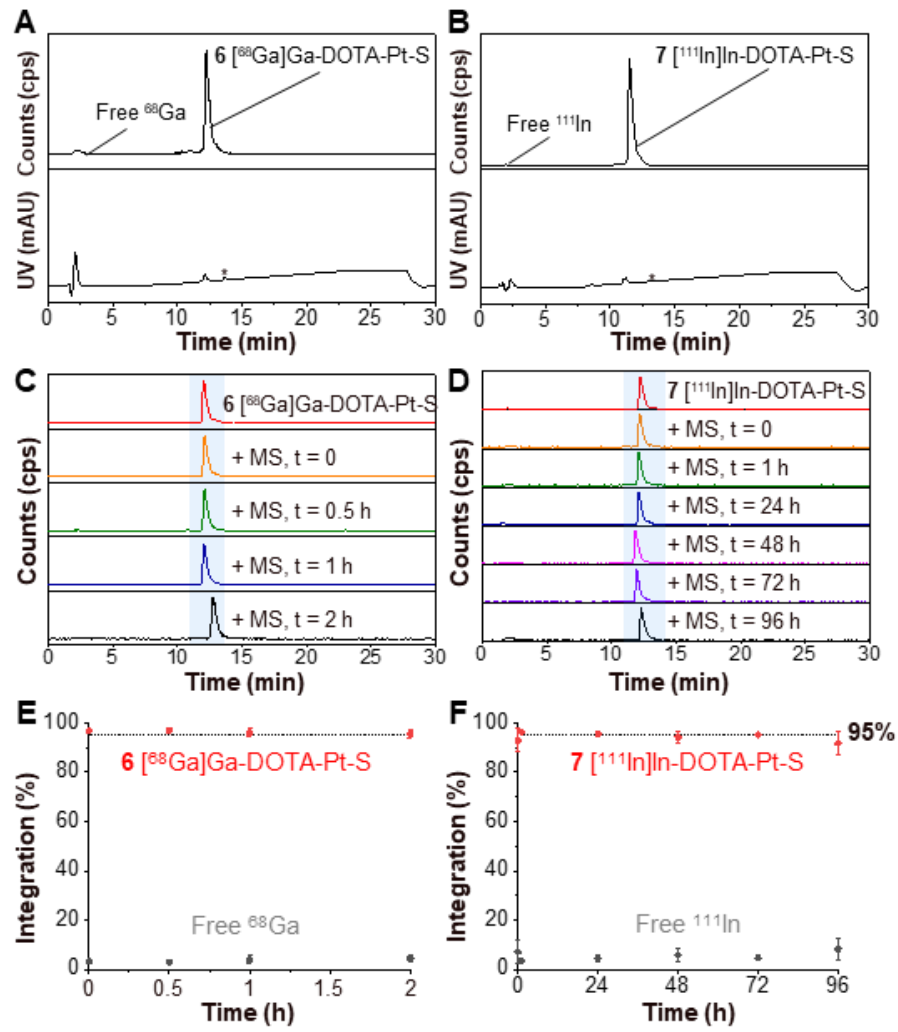

Figure 2. Complexes $\mathbf{6}$ and $\mathbf{7}$ can be obtained in greater than 95\% radiochemical yield (RCY) and are stable in mouse serum. Top: RadioHPLC chromatograms of A) 6 and B) 7. ${ }^{*}$ The peak at $13.7 \mathrm{~min}$ is an artefact from the column. Middle: RadioHPLC traces of C) 6 and D) 7 in mouse serum (MS) over $0-2 \mathrm{~h}$ and $0-96 \mathrm{~h}$ respectively. Instrument artifact in $\mathrm{C}, \mathrm{t}=2 \mathrm{~h}$, due to delayed injection into the column, peak appears right-shifted. Bottom: summary of serum stability for E) 6 and F) 7, dashed line indicates $95 \%$ threshold for chelated radiometal.

Free ${ }^{68} \mathrm{Ga}$ and ${ }^{111}$ In eluted at $c a .2$ min whereas the chelated product eluted at $c a .12$ min. Heating 1 with either ${ }^{68} \mathrm{GaCl}_{3}$ or ${ }^{111} \mathrm{InCl}_{3}$ under the same conditions did not result in the formation of additional radiochromatogram peaks indicating the radiometal only interacted with the secondary chelator and not with $\mathrm{Pt}^{\mathrm{II}}$-salphen (see Figures S25 and S26).

Sufficient radiotracer stability in serum is crucial as metal ion dissociation from its chelator, in presence of endogenous competitors (metal ions, ligands, proteins), could lead to accumulation in extraneous regions and hence is highly undesirable in cells and in vivo. Consequently, the 
stability of $\mathbf{6}$ and 7 in mouse serum was assessed over a period of 2 and 96 h respectively by radio-HPLC. Both radiolabelled complexes displayed excellent stability in mouse serum when incubated at $37{ }^{\circ} \mathrm{C}$ and showed no release of ${ }^{68} \mathrm{Ga}$ or ${ }^{111} \mathrm{In}$ over these time periods (Figure $2 \mathrm{C}$ 2F). The presence of only one peak in the radio-HPLC indicated that the radiometal had not been sequestered by proteins in mouse serum and that the $\mathrm{Pt}^{\mathrm{II}}$-salphen core remained intact. The high RCYs ( $\geq 95 \%)$ of $\mathbf{6}$ and 7, and the complex stability in mouse serum provided a good indication that radiometal and $\mathrm{Pt}^{\mathrm{II}}$-core were suitable for progression to in vivo studies. Compound 7 was chosen for further biological studies due to its longer half-life of ${ }^{111} \mathrm{In}$ compared to ${ }^{68} \mathrm{Ga}(2.1 \mathrm{~d} v s .68 \mathrm{~min})$, which allowed imaging over prolonged time.

In vivo distribution and clearance of 7 was studied by nanoSPECT/CT in a mouse melanoma tumour xenograft model at different time points over $72 \mathrm{~h}$ (see Figure $3 \mathrm{~A}$ for an experimental scheme). Four B16-F10 tumour-bearing NOD.Cg-Prkdc ${ }^{\text {scid }}$ Il2rg ${ }^{\text {tm1Wjl} / S z J ~(N S G) ~ w e r e ~ d o s e d ~}$ with $4.3 \pm 1.1 \mathrm{nmol}$ of complex $7(10.2 \pm 2.5 \mathrm{MBq})$ in $75 \mu \mathrm{L}$ of $0.2 \mathrm{M} \mathrm{NaOAc}$ buffer, $\mathrm{pH}$ 7.3. Prior to injection, the purity of 7 was assessed via radio-HPLC, then the solution was neutralised to $\mathrm{pH} 7.3$ using $2 \mathrm{M} \mathrm{NaOH}$ and passed through a $0.2 \mu \mathrm{m}$ sterile filter. The animals $(\mathrm{n}=3)$ were sacrificed after the last imaging scan (72 h post-injection; $c f$. Figure $3 \mathrm{~A})$ and their organs harvested to provide radioactive compound $\mathbf{7}$ distribution across different organs/tissues ('ex vivo biodistribution') by gamma-counting.

Serial SPECT imaging was used with consecutive scans started at $\mathrm{t}=0,15$ and $45 \mathrm{~min}$ as well as $72 \mathrm{~h}$ after initial compound administration ( $c f$. Figure 3A). Using this approach, we obtained serial images each indicating the in vivo distribution of compound 7, and when compared to one another, reporting on changes in compound distribution within the same animal over time. The distribution of radioactivity within each region of interest was compared to the total activity within the whole animal at any time point to provide crucial information about the accumulation of the tracer inside a particular organ or area over time. Within the first 15 min 
after administration, radioactivity was detected in the blood pool as well as in the tumour, kidneys and the bladder (Figure 3C). Notably, over the course of the experiment, there was a reduction in radioactivity in the blood pool and other regions of interests (ROIs) such as thigh muscle. Concomitantly, there was an increase in radiotracer levels detected in the kidneys/bladder indicative of renal clearance. Images acquired over $30 \mathrm{~min}$ from $\mathrm{t}=45 \mathrm{~min}$ revealed most of the radioactivity was cleared from the blood pool with the remaining radioactivity localised in the tumour, kidneys and bladder (Figure 3B-C). Notably, for all animals, there was clear evidence of compound 7 uptake in the tumour with radioactivity increasing from $6.4 \pm 0.8 \%$ of the administered dose at the first scan $(\mathrm{t}=0-15 \mathrm{~min})$ to $7.8 \pm 1.6$ $\%$ by the third scan $(\mathrm{t}=45-75 \mathrm{~min})$ (Figure $3 \mathrm{~B})$. In contrast, there was minimal activity in leg muscle over the same time span. Image quantification at $72 \mathrm{~h}$ indicated that the majority $(99.4$ $\pm 0.1 \%$ ) of the administered radioactivity was excreted by this time point. Notably, $22.8 \pm 3.7 \%$ of the remaining radioactivity at this late time point was concentrated in the tumour tissues. This indicated that complex 7 remained preferentially localised to tumour tissues demonstrating selectivity of compound uptake in tumour tissues. Tumour uptake was heterogenous, as expected for tumours of this cell line that were previously shown to present with necrotic cores (with little compound uptake in cores) and dense intact tumour cell populations in their outer rims. ${ }^{[37]}$ 

A Tumour model
Compound 7
establishment

\section{administration}
Ex vivo

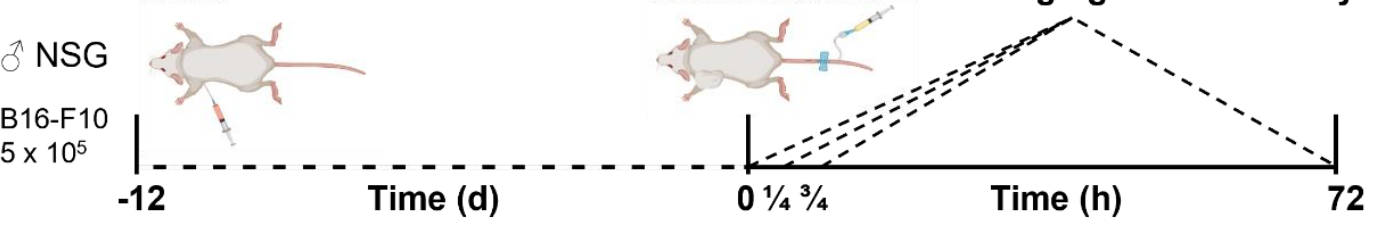

B

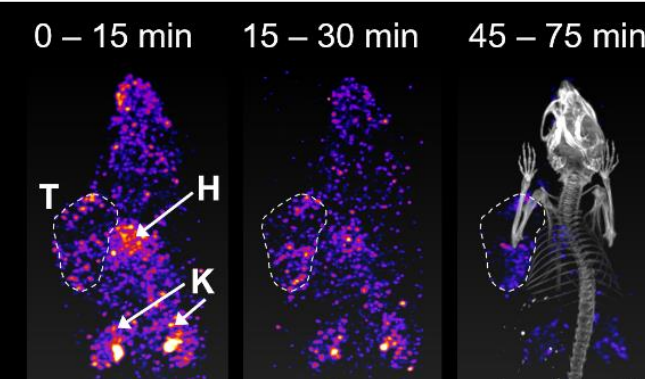

C

In vivo biodistribution
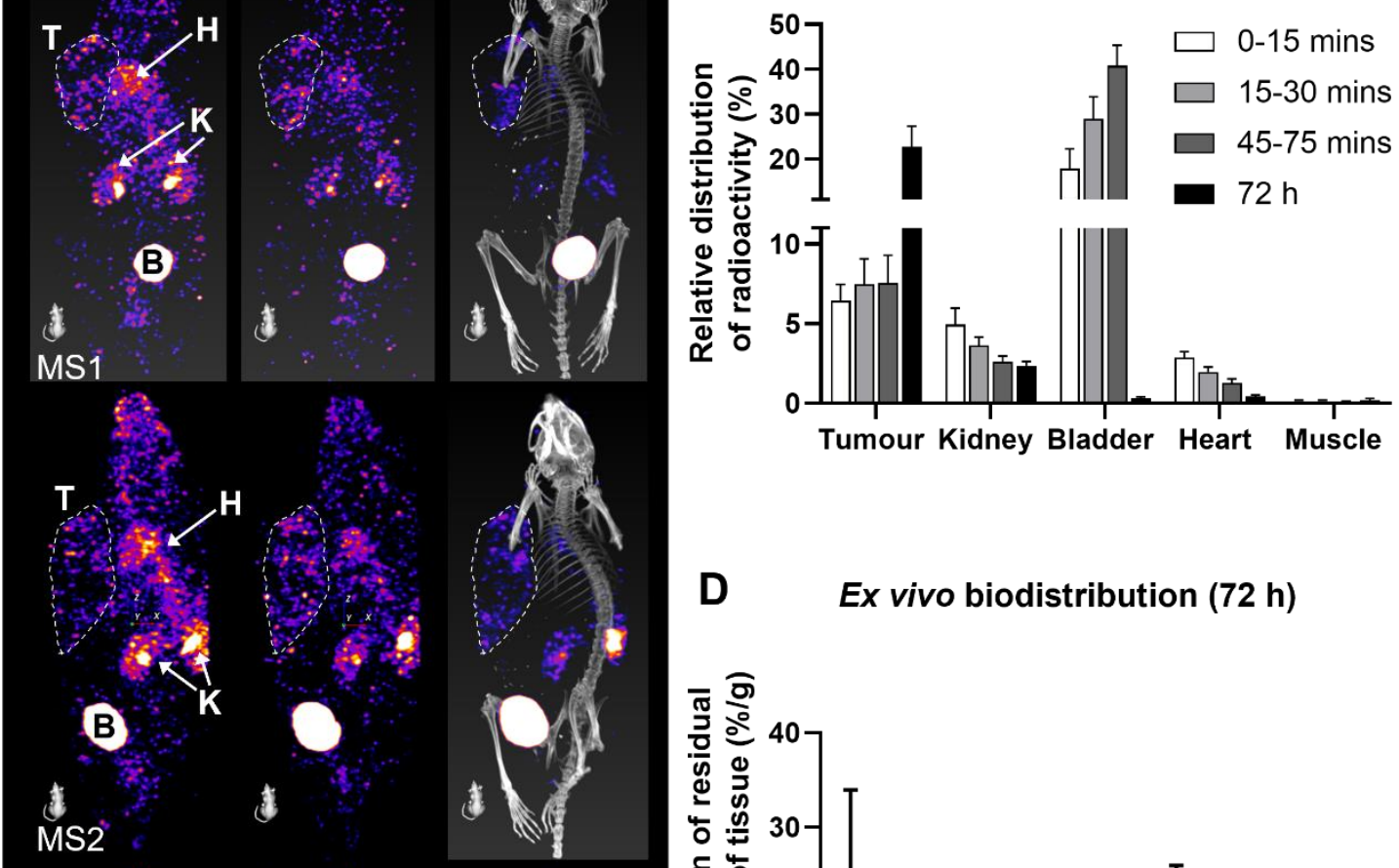

D Ex vivo biodistribution (72 h)

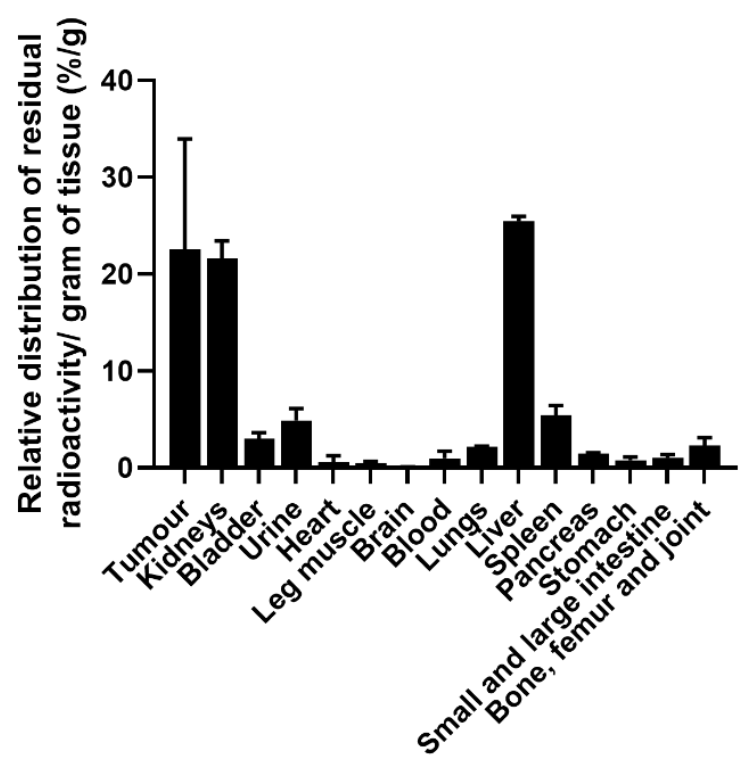

Figure 3. In vivo imaging of 7. A) Experimental scheme. B) Maximum intensity projections (MIP) of SPECT only and overlayed SPECT/CT ad indicated time points after compound $\mathbf{7}$ administration (time ranges indicates duration of full SPECT scan). Tumour regions were segmented on CT scans and are highlighted as white dashed lines. Other regions of interest identified by arrows: kidneys $(\mathrm{K})$, heart $(\mathrm{H})$, bladder $(\mathrm{B})$. C) Percentage distribution of radioactivity (\%) in key ROls, compared to the whole mouse, derived from image quantification from indicated images. D) Relative ex vivo distribution of residual radioactivity of 7 per gram of tissue in animals sacrificed $72 \mathrm{~h}$ after compound administration; mean \pm SD of $\mathrm{N}=3$ animals. Note: the bladder and urine were recorded together for in vivo images and separately for ex vivo analysis. 
In vivo imaging results were complemented by ex vivo gamma counting of radioactivity in harvested tissues $72 \mathrm{~h}$ after compound 7 administration (Figure 3D). The highest amount of radioactivity was found in liver, tumour and kidneys. Overall, our in vivo and ex vivo data indicated that compound 7 localized to tumours and remained there enriched compared to other tissues while excretion removed most of compound 7 from the animal within $72 \mathrm{~h}$. The latter is important for future potential application of compound 7 and/or derivatives as diagnostic tools to monitor changes of G4 DNA levels, for example, during treatment.

In conclusion, we demonstrated for the first time the use of SPECT/CT to assess the in vivo distribution of a well-established G4 DNA binder tethered to a secondary chelator that enabled its radiolabelling. In vitro, the presence of the DOTA-In ${ }^{\mathrm{III}}$ complex did not affect the DNA binding properties of the $\mathrm{Pt}^{\mathrm{II}}$-salphen core. We demonstrated that the novel DOTA-conjugated $\mathrm{Pt}^{\mathrm{II}}$-salphen 4 could be radiolabelled with high RCY using ${ }^{68} \mathrm{GaCl}_{3}$ and ${ }^{111} \mathrm{InCl}_{3}$, and the resulting di-metallic complexes displayed excellent stabilities in mouse serum. Importantly, we also assessed the in vivo distribution and clearance of the $\mathrm{Pt}^{\mathrm{II}}-\mathrm{In}^{\mathrm{III}}$ complex 7 in a melanoma mouse model, as imaged by SPECT/CT and corroborated results with ex vivo analysis of radioactivity in harvested tissues. Our results indicated that 7 is rapidly cleared renally and is localised to the tumour site, with its presence in the tumours observed even $72 \mathrm{~h}$ after intravenous administration. We envisage that this approach, which utilises the high sensitivity and superior depth penetration properties of nuclear imaging, could be extended for use with other G4 binders to provide crucial insights into the drugs' distribution and clearance profiles in live mammals. This could pave the way in the development of G4-binders with improved whole-body distribution, clearance, and favourable pharmacokinetics. 


\section{Acknowledgements}

RL was supported by the Engineering and Physical Sciences Research Council (EPSRC) through a studentship. Animal experiments were supported by a Cancer Research UK grant [C48390/A21153] to GOF. The authors received further support from the National Institute for Health Research (NIHR) Biomedical Research Centre based at Guy's and St Thomas' NHS Foundation Trust and King's College London; and the Wellcome/EPSRC Centre for Medical Engineering at King's College London [WT 203148/Z/16/Z]. The views expressed are those of the authors and not necessarily those of the NIHR, the National Health Service or the Department of Health. Dr. Fahad Al-Salemeel is acknowledged for technical assistance for in vivo experiments.

\section{Conflict of interest}

The authors declare no conflict of interest.

\section{References}

[1] S. Neidle, Nat. Rev. Chem. 2017, 1, 0041.

[2] R. Hansel-Hertsch, M. Di Antonio, S. Balasubramanian, Nat. Rev. Mol. Cell Biol. 2017, 18, 279-284.

[3] D. Varshney, J. Spiegel, K. Zyner, D. Tannahill, S. Balasubramanian, Nat. Rev. Mol. Cell Biol. 2020, 21, 459-474.

[4] K. Paeschke, P. Burkovics, Curr. Genet. 2021, 67, 225-230.

[5] S. Neidle, Annu. Rep. Med. Chem. 2020, 54, 517-546. 
[6] R. Chaudhuri, S. Bhattacharya, J. Dash, S. Bhattacharya, J. Med. Chem. 2021, 64, 4270.

[7] E. Ruggiero, S. N. Richter, Nucleic Acids Res. 2018, 46, 3270-3283.

[8] S. Asamitsu, T. Bando, H. Sugiyama, Chem. Eur. J. 2019, 25, 417-430.

[9] V. Dhamodharan, P. I. Pradeepkumar, ACS Chem. Biol. 2019, 14, 2102-2114.

[10] L. Savva, S. N. Georgiades, Molecules 2021, 26, 841.

[11] E. Largy, A. Granzhan, F. Hamon, D. Verga, M.-P. Teulade-Fichou, Top. Curr. Chem. 2013, 330, 111-178.

[12] D. Monchaud, Annu. Rep. Med. Chem. 2020, 54, 113-140.

[13] B. R. Vummidi, J. Alzeer, N. W. Luedtke, ChemBioChem 2013, 14, 540-558.

[14] F. Raguseo, S. Chowdhury, A. Minard, M. Di Antonio, Chem. Commun. 2020, 56, $1317-1324$.

[15] M. Di Antonio, A. Ponjavic, A. Radzevicius, R. T. Ranasinghe, M. Catalano, X. Zhang, J. Shen, L.-M. Needham, S. F. Lee, D. Klenerman, S. Balasubramanian, Nat. Chem. 2020, 12, 832-837.

[16] A. Shivalingam, M. A. Izquierdo, A. L. Marois, A. Vysniauskas, K. Suhling, M. K. Kuimova, R. Vilar, Nat. Commun. 2015, 6, 8178.

[17] P. A. Summers, B. W. Lewis, J. Gonzalez-Garcia, R. M. Porreca, A. H. M. Lim, P. Cadinu, N. Martin-Pintado, D. J. Mann, J. B. Edel, J. B. Vannier, M. K. Kuimova, R. Vilar, Nat. Commun. 2021, 12, 162.

[18] T. Kench, R. Vilar, Annu. Rep. Med. Chem. 2020, 54, 485-515.

[19] S. N. Georgiades, N. H. Abd Karim, K. Suntharalingam, R. Vilar, Angew. Chem., Int. Ed. 2010, 49, 4020-4034.

[20] J. E. Reed, A. A. Arnal, S. Neidle, R. Vilar, J. Am. Chem. Soc. 2006, 128, 5992-5993. 
[21] A. Arola-Arnal, J. Benet-Buchholz, S. Neidle, R. Vilar, Inorg. Chem. 2008, 47, 11910-11919.

[22] P. Wu, D.-L. Ma, C.-H. Leung, S.-C. Yan, N. Zhu, R. Abagyan, C.-M. Che, Chem. Eur. J. 2009, 15, 13008-13021, S13008/13001-S13008/13017.

[23] N. H. Campbell, N. H. A. Karim, G. N. Parkinson, M. Gunaratnam, V. Petrucci, A. K. Todd, R. Vilar, S. Neidle, J. Med. Chem. 2012, 55, 209-222.

[24] L. Lecarme, E. Prado, A. D. Rache, M.-L. Nicolau-Travers, R. Bonnet, A. v. D. Heyden, C. Philouze, D. Gomez, J.-L. Mergny, H. Jamet, E. Defrancq, O. Jarjayes, F. Thomas, Inorg. Chem. 2014, 53, 12519-12531.

[25] A. Terenzi, R. Bonsignore, A. Spinello, C. Gentile, A. Martorana, C. Ducani, B. Hogberg, A. M. Almerico, A. Lauria, G. Barone, RSC Adv. 2014, 4, 33245-33256.

[26] K. J. Davis, C. Richardson, J. L. Beck, B. M. Knowles, A. Guedin, J.-L. Mergny, A. C. Willis, S. F. Ralph, Dalton Trans. 2015, 44, 3136-3150.

[27] A. Ali, M. Kamra, S. Roy, K. Muniyappa, S. Bhattacharya, Chem. Asian J. 2016, 11, $2542-2554$.

[28] C.-Q. Zhou, T.-C. Liao, Z.-Q. Li, J. Gonzalez-Garcia, M. Reynolds, M. Zou, R. Vilar, Chem. Eur. J. 2017, 23, 4713-4722.

[29] S. Bandeira, J. Gonzalez-Garcia, E. Pensa, T. Albrecht, R. Vilar, Angew. Chem., Int. Ed. 2018, 57, 310-313.

[30] C. L. Ruehl, A. H. M. Lim, T. Kench, D. J. Mann, R. Vilar, Chem. Eur. J. 2019, 25, 9691-9700.

[31] N. H. Abd Karim, O. Mendoza, A. Shivalingam, A. J. Thompson, S. Ghosh, M. K. Kuimova, R. Vilar, RSC Adv. 2014, 4, 3355-3363.

[32] T. Kench, P. A. Summers, M. K. Kuimova, J. E. M. Lewis, R. Vilar, Angew. Chem., Int. Ed. 2021, 60, 10928-10934. 
[33] S. Banerjee, M. S. Capper, G. J. Clarkson, H. Huang, P. J. Sadler, Polyhedron 2019, $172,157-166$.

[34] C. Marchetti, K. G. Zyner, S. A. Ohnmacht, M. Robson, S. M. Haider, J. P. Morton, G. Marsico, T. Vo, S. Laughlin-Toth, A. A. Ahmed, G. Di Vita, I. Pazitna, M. Gunaratnam, R. J. Besser, A. C. G. Andrade, S. Diocou, J. A. Pike, D. Tannahill, R. B. Pedley, T. R. J. Evans, W. D. Wilson, S. Balasubramanian, S. Neidle, J. Med. Chem. 2018, 61, 2500-2517.

[35] S. A. Ohnmacht, C. Marchetti, M. Gunaratnam, R. J. Besser, S. M. Haider, V. G. Di, S. Neidle, H. L. Lowe, M. Mellinas-Gomez, S. Diocou, M. Robson, R. B. Pedley, J. A. Hartley, J. Sponer, B. Islam, Sci Rep 2015, 5, 11385.

[36] M. Khosravifarsani, S. Ait-Mohand, B. Paquette, L. Sanche, B. Guerin, J. Med. Chem. 2021, 64, 6765-6776.

[37] S. A. Cormier, A. G. Taranova, C. Bedient, T. Nguyen, C. Protheroe, R. Pero, D. Dimina, S. I. Ochkur, K. O'Neill, D. Colbert, T. R. Lombari, S. Constant, M. P. McGarry, J. J. Lee, N. A. Lee, J. Leukocyte Biol. 2006, 79, 1131-1139. 


\section{Graphical Abstract}

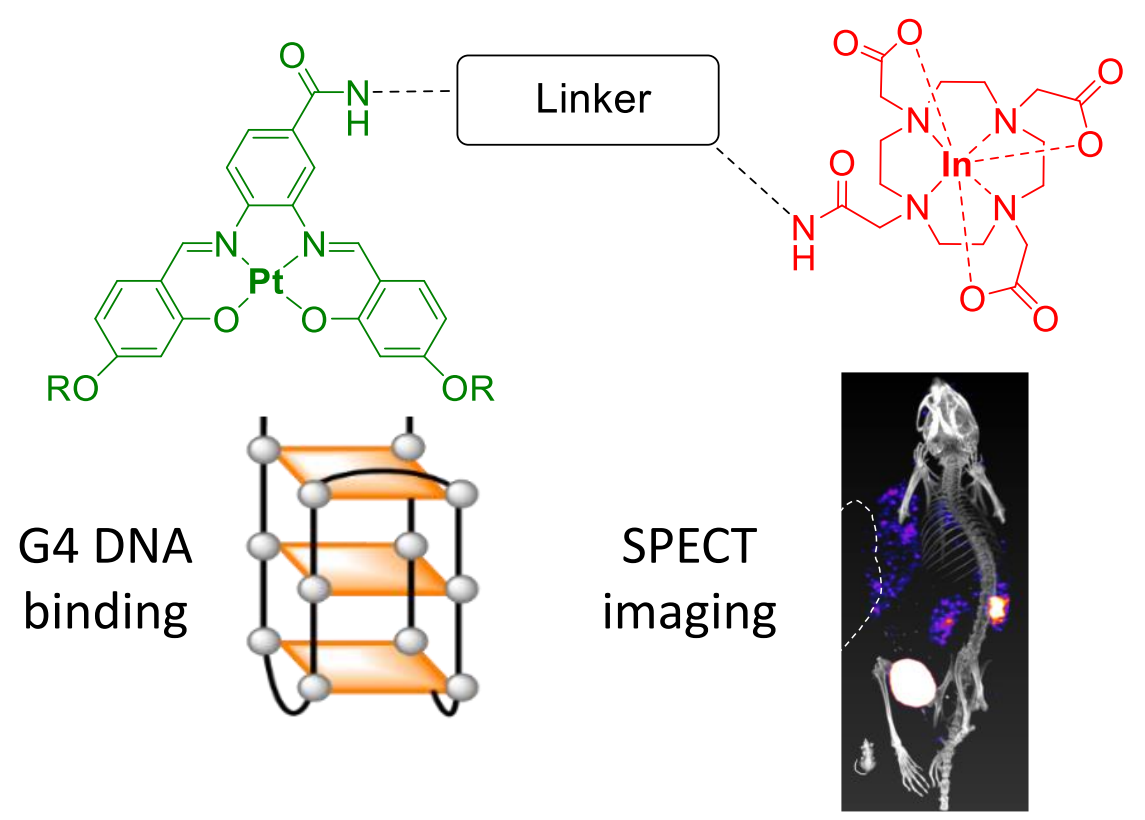

